\title{
The Echocardiogram after Pericardiectomy
}

\author{
Bahram Eslami, M.D., F.A.C.C., David Rortman, M.D., \\ Robert B. KARP, M.D., F.A.C.G., and L. Thomas \\ ShefField, M. D., F.A.C.C.
}

\begin{abstract}
Summary
Many factors may affect the interventricular septal motion. This study measures the effect of pericardiectomy on septal motion in 9 patients who were evaluated 1 week to 58 months after pericardiectomy. Echocardiography was performed with the patient in recumbent position with the special care to record motion of the muscular septum and not that of the aorta. No patient had left bundle branch block, angina, myocardial infarction, pericardial effusion or right ventricular volume overload. Septal motion was paradoxical in 7 , normal in 1 and could not be evaluated in 1 patient. The mean value of the right ventricular internal dimension was normal. Two of 9 patients had technically satisfactory echocardiograms preoperatively. Septal motion was normal in both, and both developed paradoxical septal motion postoperatively. We conclude that paradoxical septal motion follows pericardiectomy, but in contrast with other causes of this finding right ventricular internal dimension remains normal.
\end{abstract}

\section{Additional Indexing Words :}

Paradoxical septal motion Differential diagnosis

$\mathrm{E}^{\mathrm{c}}$ CHOCARDIOGRAPHIC significance of combined abnormal septal motion and increased right ventricular internal dimension in the diagnosis of right ventricular volume overload has been established. ${ }^{1-7)} \mathrm{Ab}$ normal septal motion has also been described in left bundle branch block, ${ }^{8,9}$, coronary artery disease, ${ }^{10}$ ) following aortic valve replacement, ${ }^{10}$ ) in WolffParkinson-White syndrome ${ }^{11}$ and in the majority of individuals who have undergone successful closure of an atrial septal defect. ${ }^{6}$ )

This retrospective study was undertaken to determine the echocardio-

From the Departments of Medicine and Surgery, University of Alabama School of Mecicine, Birmingham, Alabama 35294, U.S.A.

Supported in part by Cardiovascular Program Project Grant HE-11310 of the National Heart. Lung, and Blood Institute.

This work was presented at the 7 th European Congress of Cardiology, Amsterdam, Netherlands, July 20-25, 1976.

Address for reprint: Dr. Bahram Eslami, Tehran National University, Saadatabad Medical Center, Evin, Tehran, Iran (or inquire of Dr. Sheffield).

Received for publication April 17, 1978. 
graphic features of pericardiectomy and its effect on the motion of the ventricular septum which was partly similar to that observed in right ventricular volume overload.

\section{Patients AND Methods}

A total of 9 patients were evaluated 7 days to 58 months (mean, 24 months) after pericardiectomy. There were 4 women and 5 men with ages ranging from 20 to 63 years (mean, 46 years). Six patients had constrictive pericarditis presumed tuberculous, and 3 patients had recurrent (probably viral) pericarditis. Pericardiectomy was carried out through a left anterolateral thoracotomy, with removal of pericardium and its adhesions from phrenic nerve to phrenic nerve.

Echocardiography was performed using an Ekoline-20 ultrasonoscope, a $2.25 \mathrm{MHz}$ transducer of $7.5 \mathrm{~cm}$ focal length, $1.3 \mathrm{~cm}$ in diameter, and an Irex strip chart recorder. With the patient in a recumbent position, scanning of the heart was carried out by placing the transducer at the fourth intercostal space and aim-

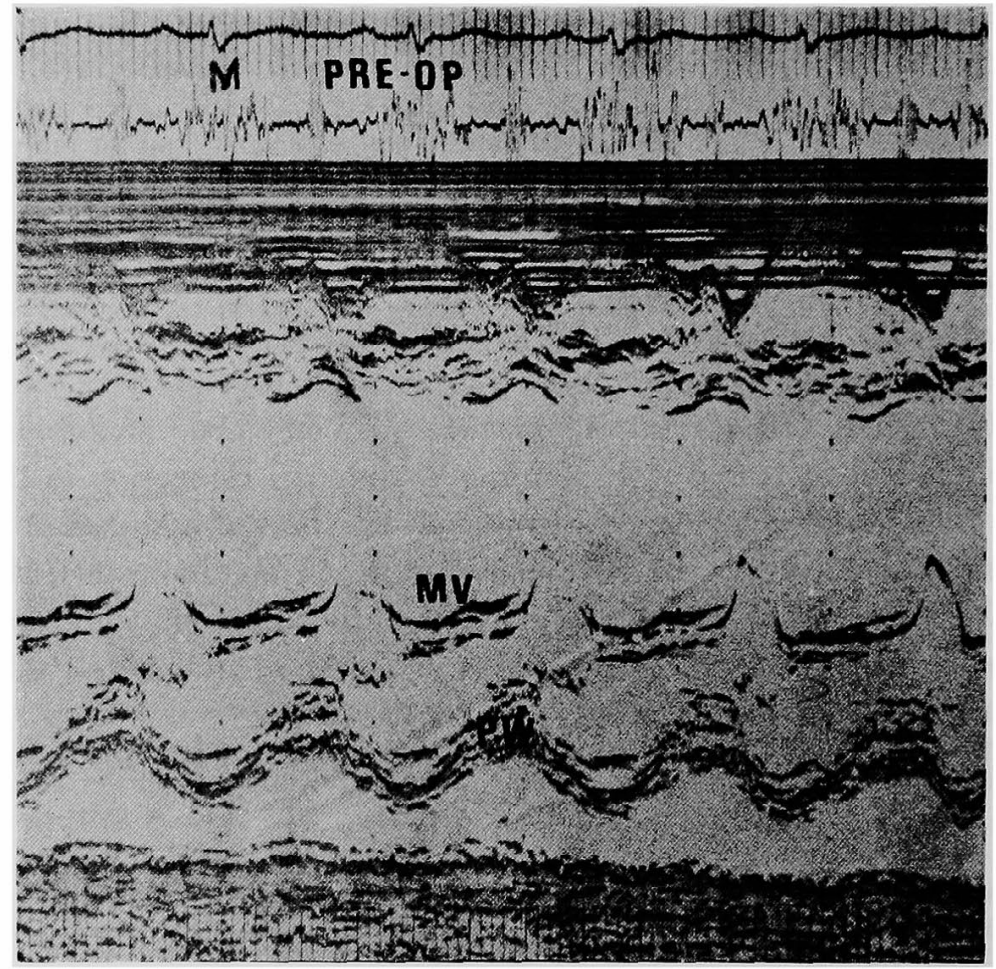

Fig. 1. Preoperative echocardiogram showing normal septal motion and considerable pericardial effusion. Note that the septum begins to move posteriorly with the $\mathbf{R}$ wave of the electrocardiogram and reaches its maximum posterior position at the end of systole. MV: mitral valve, PW: posterior wall of left ventricle. 
ing the ultrasonic beam from the aortic root to the apex of the left ventricle. Special care was taken to record motion of the muscular septum and to avoid the membranous septum close to the aorta whereby a falsely abnormal motion is not uncommon (Fig. 1). Paradoxical septal motion (type A) was defined as right and left sides of the interventricular septum moving anteriorly during ventricular systole. Right and left ventricular internal dimensions and interventricular septal thickness were measured at end-diastole.

\section{Results}

Clinical improvement was noted in all patients postoperatively. All but 2 were in sinus rhythm. One individual had trivial aortic incompetence. No patient had left bundle branch block, fascicular block, or myocardial infarction.

Paradoxical septal motion (type A) was observed in 7 patients, normal motion of the septum in 1, and it could not be evaluated in 1 patient (Fig. 2).

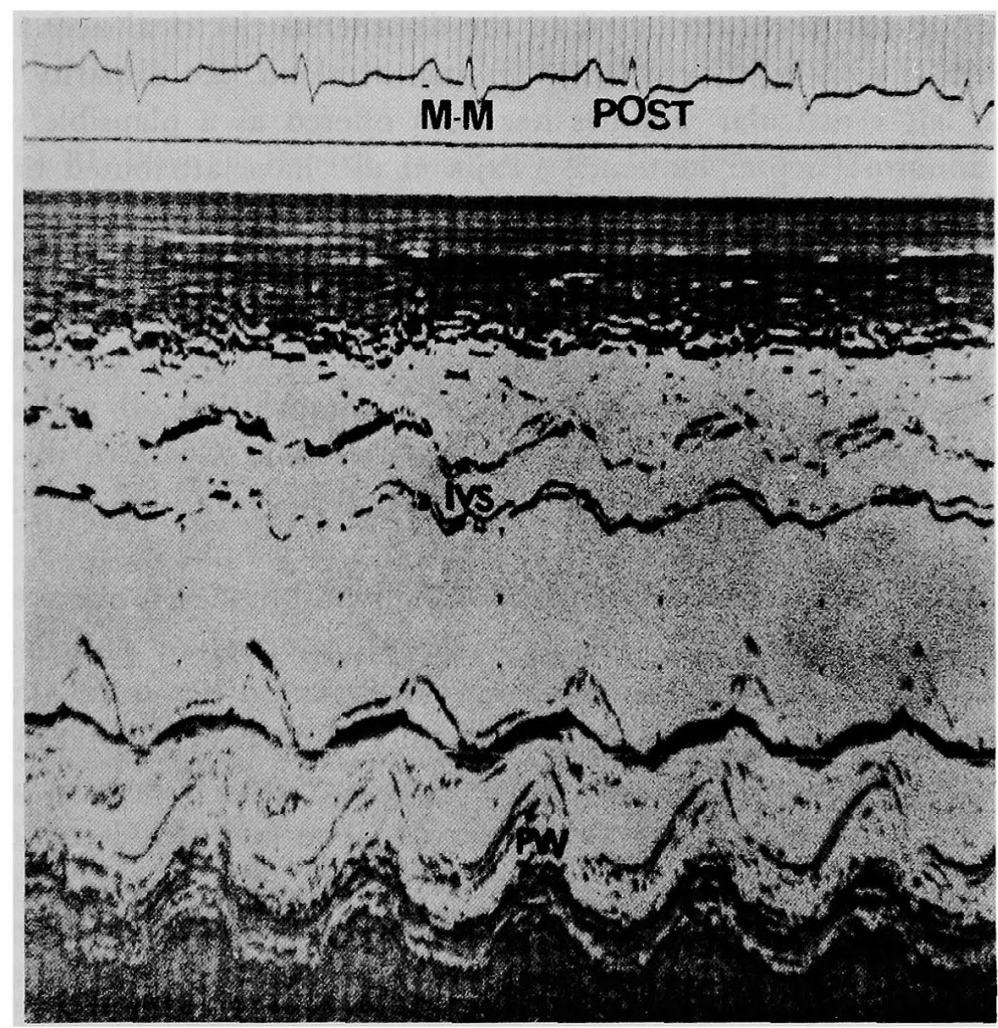

Fig. 2. Postoperative echocardiogram of the same patient, exhibiting paradoxical septal motion. In contrast with the previous figure, the septum begins to move anteriorly following the $R$ wave and reaches its maximum anterior position at the end of systole. Note that the excursion of the left ventricular posterior wall is exaggerated. IVS: interventricular septum. 
Right ventricular internal dimension ranged from $1.3 \mathrm{~cm}$ to $2.2 \mathrm{~cm}$ in 8 patients, with the mean of $1.82 \mathrm{~cm}$. Interventricular septal thickness ranged from 0.6 to $1.25 \mathrm{~cm}$ (mean $=0.98 \mathrm{~cm}$ ). The ratio, right ventricular dimension/left ventricular dimension had a mean value of 0.27 (range: 0.22 0.37 ) in 4 patients with paradoxical septal motion in whom left ventricular dimensions could be measured. Three patients had preoperative echograms. Septal motion was normal in 2 and could not be evaluated in 1. Septal motion changed from normal to paradoxical in the 2 patients with legible preoperative echocardiograms.

\section{Discussion}

Although the exact mechanism of production of abnormal septal motion observed in several disorders remains obscure, some tentative explanations have been offered. In patients with left bundle branch block the abnormal septal motion has been attributed to the disordered electrical activation. ${ }^{8,9)}$ In individuals with right ventricular volume overload, the disparity between right and left ventricular volumes has been offered as a plausible explanation for abnormal septal motion. ${ }^{2}$ Tajik et $\mathrm{al}^{3)}$ have attributed the septal motion abnormalities to the magnitude of left to right shunt. Meyer et $\mathrm{al}^{4}{ }^{4}$ relate the abnormal septal motion to the net anterior systolic motion of the entire heart in the presence of severe right ventricular dilatation. Laurenceau and Dumesnil ${ }^{12}$ have explained abnormal septal motion on the basis of right ventricular enlargement and have suggested that all patients with right ventricular to left ventricular ratio greater than 0.6 have this abnormality. This ratio was 0.37 in the 4 of our patients in whom it was measurable.

In many instances, however, paradoxical septal motion is observed in the absence of right ventricular volume overload, conduction disturbances of myocardial infarction, and no satisfactory explanation has been offered for these. Kerber et $\mathrm{al}^{6 /}$ have observed persistence of abnormal septal motion in the majority of patients who have undergone successful closure of an atrial septal defect. We have commonly observed abnormal septal motion after aortic valve replacement, mitral valve replaccment, open mitral commissurotomy and up to 11 years after repair of atrial septal defects. However, we have not observed abnormal septal motion following closed mitral commissurotomy.

An explanation for abnormal septal motion in patients after pericardiectomy and in many individuals after heart surgery may lie in the anatomical and functional contribution of an intact pericardium to normal septal motion. 
The restrictive function of the pericardium on the heart has been previously documented both in animals and man. ${ }^{13}$ ) This important function no longer exists in pericardiectomized patients and many who have had pericardiotomies. Under these circumstances, it is possible that the entire heart moves forward in systole, thereby systolic posterior movement of the septum is counterbalanced by a greater antcrior motion, resulting in a net anterior septal motion. A similar observation has been made by Payvandi et $a^{14)}$, who found paradoxical septal motion in pericardiectomized individuals and in patients with congenital absence of the pericardium. This hypothesis would also explain the abnormal septal motion in patients who have undergone open cardiac surgery and in whom the pericardium has either been left open or closed loosely with the loss of its functional integrity. Retention of normal septal motion observed in patients after closed mitral commissurotomy can easily be explained since the pericardium is not widely opened in these patients, and is closed securely after commissurotomy.

\section{REFERENCES}

1. Popp RL, Wolfe SB, Hirata T, Feigenbaum $\mathrm{H}$ : Estimation of right and left ventricular size by ultrasound: a study of the echoes from the interventricular septum. Am $\mathrm{J}$ Cardiol 24: 523,1969

2. Diamond MA, Dillon JC, Haine CL, Chang S, Feigenbaum H: Echocardiographic features of atrial septal defect. Girculation 43: 129, 1971

3. Tajik AJ, Gau GT, Ritter DG, Schattenberg TT: Echocardiographic pattern of right ventricular diastolic volume overload in children. Circulation 46:36, 1972

4. Meyer RA, Schwartz DC, Benzing GIII, Kaplan S: Ventricular septum in right ventricular volume overload. An echocardiographic study. Am J Cardiol 30: 349, 1972.

5. McCann WD, Harbold NB Jr, Giuliani ER: The echocardiogram in right ventricular overload. JAMA 221: 1243, 1972

6. Kerber RE, Dippel WF, Abboud FM: Abnormal motion of the interventricular septum in right ventricular volume overload: experimental and clinical echocardiographic studies. Circulation 48: 86, 1973

7. Radtke WE, Tajik AJ, Gau GT Schattenberg T, Giuliani ER, Tancredi RG: Atrial septal defect. Echocardiographic observations. Ann Intern Med 84: 246, 1976

8. McDonald IG: Echocardiographic demonstration of abnormal motion of the interventricular septum in left bundle branch block. Circulation 48:272, 1973

9. Abbasi AS, Eber LM, MacAlpin RN, Kattus AA: Paradoxical motion of interventricular septum in left bundle branch block. Circulation 49: 423, 1974

10. Feigenbaum $\mathbf{H}$ : Echocardiography. Philadelphia, Lea and Febiger, p 202, 123, 1972

11. Chandra MS, Kerber RE, Brown DD, Funk DC: Echocardiography in Wolff-ParkinsonWhite syndrome. Circulation 53: 943,1976

12. Laurenceau JL, Dumesnil JG: Influence of right and left ventricular dimension on ventricular septal motion. 7th European Congress of Cardiology, Amsterdam, Netherlands, p 269, 1976 (abstr)

13. Holt JP: The normal pericardium. Am J Cardiol 26: 455, 1970

14. Payvandi MN, Kerber RE: Congenital and acquired absence of the pericardium. An echocardiographic mimic of right ventricular volume overlod. Circulation 51-52 (Suppl II): II $-79,1975$ (abstr) 